\title{
Tweets, Google Trends and Sovereign Spreads in the GIIPS
}

\author{
Theologos Dergiades, Costas Milas \\ and Theodore Panagiotidis
}

GreeSE Paper No.78

Hellenic Observatory Papers on Greece and Southeast Europe

OCTOBER 2013 


\section{TABLE OF CONTENTS}

ABSTRACT _

1. Introduction _ـ 1

2. Data and Methodology ___ 5

2.1. Data description _ـ 5

2.2. Methodology ___ 7

3. Empirical results __ 9

4. Discussion and concluding remarks__ 14

References _ـ 17

\section{Acknowledgements}

We thank Richard Baillie (Michigan State University), Roberto De Santis (ECB), Carlo Favero (Bocconi University), Chris Florackis (Liverpool University), llias Lekkos (Piraeus Bank), Marcus Miller (University of Warwick) and Thanasis Stengos (University of Guelph) for useful comments. Any remaining errors are our own. 


\title{
Tweets, Google Trends and Sovereign Spreads in the GIIPS
}

\author{
Theologos Dergiades", Costas Milas* \\ and Theodore Panagiotidis ${ }^{+}$
}

\section{ABSTRACT}

We examine whether the information contained in social media (Twitter \& Facebook) and web search queries (Google) influences financial markets. Using a multivariate system and focussing on Eurozone's peripheral countries, the GIIPS (Greece, Ireland, Italy, Portugal and Spain), we show that social media discussion and search-related queries for the Greek debt crisis provide significant short-run information primarily for the Greek-German government bond yield differential even when other financial control variables (default risk, liquidity risk and international risk) are accounted for, and to a much lesser extent for Portuguese and Italian sovereign yield differentials.

Keywords: Google, social media, Greek crisis, frequency domain analysis, GIIPS.

JEL Classification: C10, G01, G02.

\footnotetext{
\# School of Science and Technology, International Hellenic University, Greece Email: t.dergiades@ihu.edu.gr

"Management School, University of Liverpool, United Kingdom and Rimini Centre for Economic, Analysis, Italy, Email: costas.milas@liverpool.ac.uk(corresponding author).

${ }^{+}$Department of Economics, University of Macedonia, Greece and Rimini Centre for Economic Analysis, Italy Email: tpanag@uom.edu.gr
} 



\section{Tweets, Google Trends and Sovereign Spreads in the GIIPS}

\section{Introduction}

Social media have progressively become a popular open forum for analysing economic/financial topics and a field where the public sentiment is reflected in real time. They are widely used by influential economic commentators, policymakers and their followers. For instance, 2008 Nobel Laureate in Economics and New York Columnist Paul Krugman had, at the time of writing, 1,083,072 Twitter account followers, whereas International Monetary Fund Managing Director Christine Lagarde had 146,805 Twitter followers. Further, "hot" economic topics like the (ongoing) Eurozone crisis and the Greek debt crisis are covered and discussed in great detail by dedicated websites (for instance in the The Wall Street Journal and The Financial Times). It has been argued that this "storehouse" of precious information might be contributing to the explanation of upcoming movements in financial markets (Geoffrey, 2012 for volatility; Pan et al. 2012, for investors' attention and stock price, Da et al., 2011; for investors' overreaction, Joseph et al., 2011 for abnormal returns). On April $18^{\text {th }} 2013$, Financial Times commentator Gillian Tett noted that investors can track investment returns with growing precision by plugging into social media. ${ }^{1}$ A recent fake tweet reflects the power of social media and the cost of inaccurate information in an era where the speed at which information travels is unprecedented. A fake tweet on April $23^{\text {rd }} 2013$

\footnotetext{
${ }^{1}$ Gillian Tett on "Markets Insight: Wake up to the Twitter effect on markets", The Financial Times, April 18, 2013.
} 
from a hacked Associated Press account (asserting that explosions at the White House had injured Barack Obama) wiped more than $\$ 130$ billion off the value of the S\&P $500 .^{2}$ In fact, it has been suggested that financial markets are more strongly influenced by negative press rumors than by fundamentals (see Hasan et al., 2012).

This paper examines the impact of the volume of activity in social media (Twitter \& Facebook) and web search queries (Google Trends) on the sovereign spread between the GIIPS (Greece, Ireland, Italy, Portugal, Spain) and the German long-term government bond yield during the Greek debt crisis. As the Greek crisis escalated, the term "Grexit" (Greece's exit from the single currency) was added to the financial vocabulary. During this period, the Greek spread rose to unprecedented levels contributing further to the risk of contagion in Eurozone's other peripheral countries. Greece, which was bailed-out twice (for $€ 110 \mathrm{bn}$ in 2010 and then again for $€ 109 b n$ in 2011), negotiated, in February 2012, a new $€ 130 \mathrm{bn}$ rescue package involving a voluntary haircut of some $53.5 \%$ on the face value of its bonds held by the private sector. Eurozone ministers agreed (in November 2012) to cut Greece's debt by a further $€ 40 \mathrm{bn}$. Ireland was bailed-out for €85bn in November 2010. Portugal was bailed-out for €78bn in May 2011. Spain was granted, in July 2012, financial assistance from the European Stability Mechanism (ESM) for up to $€ 100 \mathrm{bn}$. Despite the bail-outs, international markets remain volatile and worried that the debt levels of all GIIPS could be unsustainable (this is reflected, for instance, on Spanish and Italian government yields that

\footnotetext{
${ }^{2}$ (The Economist; see http://www.economist.com/news/finance-and-economics/21576671hacked-tweet-briefly-unnerves-stockmarket-newscrashrecover).
} 
are still elevated) posing a risk to the entire Eurozone. ${ }^{3}$ These concerns appear justifiable as the GIIPS account for around 34.3\% of Eurozone's GDP (Italy is the third and Spain is the fourth largest Eurozone economies) and run both current account deficits and high debt-to-GDP ratios. Italy accounts for $17.3 \%$ of Eurozone GDP. Spain accounts for $11 \%$ of Eurozone GDP, whereas Greece, Portugal and Ireland account for $2.3 \%, 1.9 \%$, and $1.8 \%$ of Eurozone GDP, respectively (Eurostat).

To examine the impact of the volume of activity in social media (Twitter \& Facebook) and web search queries (Google Trends) on the sovereign spreads in the GIIPS, we use the frequency domain causality test of Breitung and Candelon (2006). This econometric framework provides the following advantages: (i) it distinguishes between short-run and long-run causality, (ii) it allows the identification of causal relationships even if the true interdependence between two variables is non-linear in nature, (iii) it allows us to condition upon a set of relevant variables avoiding this way potential spurious causality inference, and (iv) the test is valid in the presence of volatility clusters, a common characteristic of financial variables. We demonstrate that social media discussion and searchrelated queries for the Greek debt crisis provide significant information for explaining the spread (difference) between the cost of borrowing in Eurozone's peripheral bond market and Germany over and above the information provided by other financial control variables (idiosyncratic default risk, liquidity risk and international risk). Our main findings are

\footnotetext{
${ }^{3}$ Following from the pledge of European Central Bank President Mario Draghi to do "whatever it takes" to save the Euro (in July 2012), the European Central Bank approved (in September 2012) a plan paving the way for the bank to make unlimited purchases in struggling euro members' bond markets (such as Italy and Spain) with the aim of lowering their government bond yields. The plan was conditional on struggling governments to sign up to a euro-zone program of budgetary discipline.
} 
summarized as follows: First, there is neither short-run nor long-run causality running from the Greek spread to social media/search queries. Second, we identify short-run causality from social media/search queries to the Greek spread. Third, there is some weak (and information-set sensitive) evidence of predictability of Greek-debt related social media/search queries for Portuguese and Italian spreads; a possible reason for this finding is that the current exposure of Portuguese and Italian banks to Greek debt is higher than the exposure of Irish or Spanish banks. Unsurprisingly, as the Greek debt crisis evolved and Greek creditworthiness took a hit, the market price of Greek debt declined rapidly and consequently, banks exposed to Greek debt witnessed a weakening in their balance sheets. At the same time, the lower market price of Greek debt had an adverse impact on the value of collateral banks needed to secure wholesale funding and triggered margin calls requiring the posting of additional collateral. This form of contagion from Greece to Portugal and Italy might reflect the most likely answer (at the time of writing) to the question "who is next?". Fourth, Twitter/Facebook provides stronger evidence of significance in high frequencies relative to Google (search queries); this might be because Twitter (in particular) has become a very popular way of keeping track of news and directing "followers" to news analysis (e.g. in blogs) in an extremely speedy way.

The structure of the paper is as follows: Section 2 discusses the data and methodology. Section 3 reports our empirical results. Section 4 discusses our findings and provides some concluding remarks. 


\section{Data and Methodology}

\subsection{Data description}

We use daily time-series data related to the Greek crisis over the period from 05/20/2011 to 05/09/2013 (495 observations). The search queries index $(G)$ for key phrases related to Greek debt crisis has been retrieved from Google Trends (http://www.google.com/trends/; see Fig. 1). These phrases are: "Greek crisis", "Greek debt crisis", "Greece crisis", "Greek debt" and "Grexit". Note that in twitter \#grexit was associated with the Greek crisis and it was not possible to retrieve keywords in twitter. Hash tags (\#) were available only in twitter. Fig. 2 plots the Twitter (\#Grexit) and Facebook hits (appearances) $(T$ ) for the keyword Grexit; these cover the period from 09/01/2012 to 05/09/2013 (170 observations; our data source is: http://analytics.peoplebrowsr.com//) ${ }^{4}$. We assess the impact of both variables above on the sovereign spread $\left(S_{j}\right)$ between the 10-year government bond yield in Eurozone peripheral country $j(j=$ Greece, Ireland, Italy, Portugal, Spain) and the German government bond yield (available from Datastream; see Fig. 3 ). ${ }^{5,6}$ To do so, we condition on a number of controls: default risk, liquidity risk and international risk. We proxy the default risk $\left(D_{j}\right)$ by the difference between the 10-year Credit Default Swap (CDS) premia in country $j$ and the 10-year German CDS premia (available from Datastream; see Fig. 4). To proxy the default risk of Greece, we use the difference between the equally weighted sum of the 10-year Credit Default Swap (CDS) premia for two major Greek banks

\footnotetext{
${ }^{4}$ Note that the sample was determined by the data availability.

${ }^{5}$ Nonlinear unit root tests (Kapetanios et al., 2003) provide evidence of stationarity for $G, T$ and $S_{j}$ (available upon request).

${ }^{6}$ One might argue that GARCH effects might be present in the sovereign spreads (Fig. 3). Bodart and Candelon (2009) demonstrate that the methodology we are employing in this study is not sensitive to the presence of volatility clustering.
} 
(Alpha Bank and National Bank of Greece) and the 10-year German CDS premia. Greek debt restructuring (in February 2012) triggered the payment of Greek CDS in March 2012. Since then, these series has been discontinued. For this reason, we use the CDS information on Greece's two major banks which are positively correlated (0.58) with the Greek CDS.

Lack of attention towards liquidity risk has been cited by the President of the Federal Reserve Bank of Boston Eric Rosengren (2010) as one of the reasons explaining why the seriousness of the recent financial crisis was underestimated by economic forecasters; in fact, liquidity considerations have become a central issue in the literature only recently (see e.g. Angelini et al., 2011; Naes et al., 2011). We proxy liquidity risk ( $L_{j}$; see Fig. 5) using the differential between the bid-ask spread of the 10-year bond in country $j$ and the bid-ask spread of the 10-year German bond (see e.g. De Santis, 2012; Arghyrou and Kontonikas, 2012; Favero et al., 2010). Following De Santis (2012) and Schwarz (2010), we also use (from Bloomberg) the spread between the 10-year KfW (Kreditanstalt für Wiederaufbau) bond yield and the 10-year German government bond yield as a proxy for the Eurozone area common risk factor (E); see Fig. 5. $\mathrm{KfW}$ are German agency bonds. These bonds are less liquid than the federal government ones; however, KfW bonds carry the same default risk as they are fully guaranteed by the German federal government. Therefore, any difference should reflect "flight-to-liquidity" and "flightto-safety" considerations. We follow Arghyrou and Kontonikas (2012) in proxying international risk by the Chicago Board Options Exchange volatility index (VIX); this measures the implied volatility of S\&P 500 index options. As an alternative and broader measure, we use the 
Federal Reserve Bank of St. Louis financial stress index (FSI) which is a composite index of 18 financial variables (including VIX); see Fig. 6. FSI is available at a weekly frequency; we convert the series to daily frequency using the quadratic-match average method. The method fits a local quadratic polynomial for each observation of the low frequency series, and then uses this polynomial to fill in all observations of the high frequency series associated with the period. ${ }^{7}$

\subsection{Methodology}

For the structural bivariate system $z_{t}=\Theta(L) C^{-1} u_{t}=\Psi(L) u_{t}$ with $z_{t}=\left(x_{t}, y_{t}\right)^{\prime}$ and within the Breitung and Candelon (2006) framework (B\&C, hereafter), the non-causality hypothesis at frequency $\omega$ is tested by:

$$
M_{y \rightarrow x}(\omega)=\log \left[1+\left|\Psi_{12}\left(e^{-i \omega}\right)\right|^{2} /\left|\Psi_{11}\left(e^{-i \omega}\right)\right|^{2}\right]
$$

where $\Psi_{11}$ and $\Psi_{12}$ are derived from a VAR moving average representation. In case where ${ }^{y_{t}}$ does not cause ${ }^{x_{t}}$ at $\omega, M_{y \rightarrow x}(\omega)$ is zero and $\left|\Psi_{12}\left(e^{-i \omega}\right)\right|^{2}=0$. B\&C remedy the estimation complexity of $\left|\Psi_{12}\left(e^{-i \omega}\right)\right|^{2}$ through a set of restrictions imposed on the VAR coefficients. B\&C restate the null based on $\Psi_{12}(L)=-\left(1 / c_{22}\right) *\left(\Theta_{12}(L) /|\Theta(L)|\right) .1 / c_{22}$ is positive ${ }^{8}$ element of the $C^{-1}$ and $|\Theta(L)|$ is the determinant of $\Theta(L)$. The null hypothesis of no causality at frequency $\omega$ running from $y_{t}$ to $x_{t}$ is not rejected whenever (2) holds:

\footnotetext{
${ }^{7}$ See http://research.stlouisfed.org/publications/net/NETJan2010Appendix.pdf.

${ }^{8}$ This is due to the assumption that the variance-covariance matrix is a positive definite.
} 


$$
\left|\Theta_{12}\left(e^{-i \omega}\right)\right|=\left|\sum_{k=1}^{p} \theta_{12, k} \cos (k \omega)-\sum_{k=1}^{p} \theta_{12, k} \sin (k \omega) i\right|=0
$$

with $\theta_{12, k}$ to be element of the ${ }^{\Theta_{k}}$ matrix. The set of restrictions imposed are: $^{9}$

$$
\sum_{k=1}^{p} \theta_{12, k} \cos (k \omega)=0 \quad \text { and } \quad \sum_{k=1}^{p} \theta_{12, k} \sin (k \omega)=0
$$

If we denote $\alpha_{j}=\theta_{11, j}$ and $\beta_{j}=\theta_{12, j}$, the VAR equation that corresponds to the ${ }^{x_{t}}$ variable may be rewritten as:

$$
x_{t}=\alpha_{1} x_{t-1}+\ldots+\alpha_{p} x_{t-p}+\beta_{1} y_{t-1}+\ldots+\beta_{p} y_{t-p}+\varepsilon_{1 t}
$$

Thus, the null hypothesis is equivalent to the following set of restrictions:

$$
R(\omega) \beta=0, \quad \text { where } \beta=\left(\beta_{1}, \ldots, \beta_{p}\right)^{\prime} \text { and } R(\omega)=\left(\begin{array}{ccc}
\cos (\omega) & \ldots & \cos (p \omega) \\
\sin (\omega) & \ldots & \sin (p \omega)
\end{array}\right)
$$

(5) To assess the validity of (5) for frequencies $\omega$ that range within $(0, \pi)$, $B \& C$ compare the obtained statistic with the 0.05 critical value of the $\chi^{2}$ distribution with 2 degrees of freedom.

Hosoya (2001) proposed a method that eliminates from the variables of interest the one way feedback due to a third variable, while the initial feedback structure remains invariant. For instance, ${ }^{10}$ in the trivariate system $z_{t}=\left(x_{t}, y_{t}, m_{t}\right)^{\prime}$ let $w_{t}$ denote the projection residual vector

\footnotetext{
${ }^{9}$ Given that $\sin (k \omega)=0$ in the cases where $\omega=0$ and $\omega=\pi$, it comes that the second restriction in (3) is simply disregarded.

${ }^{10}$ In this study, we condition upon four variables. For presentation purposes, we discuss the conditioning approach using one variable. The extension to additional variables is straightforward.
} 
obtained by projecting $m_{t}$ into the Hilbert space $H\left(x_{t}, y_{t}, z_{t-1}, z_{t-2}, \ldots\right)$. Similarly, let $\kappa_{t}$ and $\delta_{t}$ represent the projection residual vectors obtained by projecting $x_{t}$ and $y_{t}$, respectively, into Hilbert space $H\left(w_{t}, w_{t-1}, \ldots\right)$. After the described transformation, Hosoya (2001) argues that a higher order conditional causality measure can be expressed equivalently by the bivariate causality measure $M_{y \rightarrow x / m}(\omega) \equiv M_{\delta \rightarrow \kappa}(\omega)$.

\section{Empirical results}

Following section's 2 notation, ${ }^{x_{t}}$ refers to the target variable while $y_{t}$ refers to the causing variable. Depending on the examined hypothesis each time, target or causing variable may be one of the $S_{j}, G$ or $T$. Finally, the $m_{t}$ vector, upon which we condition, includes proxies for idiosyncratic default risk $\left(D_{j}\right)$, liquidity risk $\left(L_{j}\right)$, Eurozone risk $(E)$ and international risk (VIX or FSI).

Using the B\&C test, we disentangle short- and long-run predictability among the variables of interest. Results for Greece (with and without conditioning) are presented in Figs. 7-10 and summarized in Table 1. The null hypothesis of no predictability running from $G$ towards $S_{\text {Greece }}$ is rejected for the $B \& C$ measure (bold line), at the 0.05 significance level, when $\omega \in[0.78 \pi, \pi] \cup[0.10 \pi, 0.69 \pi]$, (Fig. 7). This implies that medium size and high frequencies of $G$ (short-run cyclical components), with wave lengths of less than 2.56 days $(2 \pi / \omega=6.28 / 2.45=2.56)$ as well as between 2.89 and 20.26 days, are those that offer predictive power with respect to $S_{\text {Greece. }}$. When the B\&C test is re-conducted, after the Hosoya's (2001) conditioning approach, the revealed predictability pattern is 
comparable to the bivariate case irrespective of which international risk proxy is employed (VIX or FSI). The joint range of frequencies in which predictability is supported, correspond to cyclical components with wave lengths of less than 2.26 days $(\omega \in[0.88 \pi, \pi])$ and between 3.22 and 15.32 days $(\omega \in[0.31 \pi, 0.61 \pi])$. Raggedly, it can be argued that the short-run cyclical components of $G$ series with wave lengths of less than two weeks are capable of offering additional information with respect to the future movements of $S_{\text {Greece. }}$. At the same time there is no evidence of long-run causality. On the other hand, the null hypothesis of no causality at the opposite direction is rejected for the entire range of frequencies. The latter also holds when conditioning takes place (see Fig. 9).

The same testing procedure (with and without conditioning; with the same control variables) is implemented to the Twitter \& Facebook hits (appearances) in order to assess its impact on the Greek spreads. The non-Granger causality hypothesis running from $T$ to $S_{\text {Greece, }}$ is rejected for the $B \& C$ measure (bold line) at the 0.05 significance level when $\omega \in$ $[0.76 \pi, \pi]$, (Fig. 8). The abovementioned range of frequencies corresponds to wave lengths of less than 2.63 days. Therefore, only short-run causality is established. Similar pattern as above, with relatively larger range of frequencies, contributing significantly in the prediction of $S_{\text {Greece, }}$ is uncovered under the Hosoya's (2001) conditioning approach. The joint range of frequencies with significant causality coincides with the range of the bivariate unconditioned case, that is $\omega \in$ $[0.76 \pi, \pi]$. Again, we find no credible empirical evidence to support the reverse hypothesis; the same holds even when we condition upon the 
set of variables included in $m_{t}$ (see Fig. 10). Comparing Figs. 7 and 8, we note that Twitter \& Facebook provide more pronounced evidence of short-run predictability in terms of significance relative to Google (search queries); we return to this issue in the next section.

Figs. 11-18 report our findings for the remaining GIIPS whereas a summary of all results for the GIIPS is reported in Table 1. We find feeble and non-systematic evidence of short-run predictability of the Twitter\&Facebook variable (only for the case without conditioning) of up to 2.65 days for the 10-year spread in Portugal (see Fig. 17) and qualitatively similar evidence of short-run to medium-run predictability (with reference to the Google variable and conditioning when the VIX is used) of between 2.92 and 3.93 days for Italy (see Fig. 12). Hence, there is sporadic evidence of predictability (sensitive to the information set used) for Portugal (which, like Greece, is a relatively small Eurozone economy) and Italy. It goes without saying that these results should be treated with caution. A potential explanation for our findings is that at the time of the Portuguese bailout, Portuguese banks, followed by Italian banks, had a higher exposure to Greek public and private debt than any of the remaining GIIPS. Indeed, Bank of International Settlements (BIS) data showed that in June 2011, Portuguese banks had some $\$ 10.08 \mathrm{bn}$ exposure (or $6.73 \%$ of their total exposure around the world) followed by a $\$ 3.88 \mathrm{bn}$ exposure (or $0.40 \%$ of total exposure) for Italian banks, $\$ 0.77 \mathrm{bn}$ (or $0.21 \%$ of total exposure) for Irish banks and $\$ 1.22 \mathrm{bn}$ (or $0.1 \%$ of total exposure) for Spanish banks. Following the Greek debt restructuring, the exposure to Greek debt was reduced; yet, Portuguese banks, followed by Italian banks, remained more exposed to 
Greek debt than the others. According to the latest BIS data (published in June 2013), the exposure of Portuguese banks to Greek debt had dropped, in December 2012, to $\$ 7.34 \mathrm{bn}$ (or $6.16 \%$ of their total exposure around the world). The exposure of Italian banks to Greek debt had dropped to $\$ 1.0 \mathrm{bn}$ (or $0.12 \%$ of total exposure), for the Irish banks to $\$ 0.11 \mathrm{bn}$ (or $0.07 \%$ of total exposure) and for the Spanish banks to $\$ 0.76 \mathrm{bn}$ (or $0.05 \%$ of total exposure). This argument is in line with the evidence of Mink and de Haan (2013) who rely on an event study approach and employ daily data to identify significant effects of news about the Greek bailout on stock price returns in European banks (irrespective of their exposure to the remaining GIPS; the definition of Mink and De Haan excludes Italy). They also find that that news about the Greek economic situation and the Greek bailout has led to abnormal returns on sovereign bonds for the GIPS with a larger impact in the case of Portugal and a lower impact in the case of Ireland and Spain.

To sum up, we show that Greek debt crisis related information in social media (Twitter \& Facebook) and web search queries (Google) does influence financial markets. This is mainly so for Greece, and to a much lesser extent for Portugal and Italy. This could be viewed as a weak signal of contagion from Greece to (some of) the remaining GIIPS in the sense that social media discussion and search queries related to the Greek debt crisis carry some predictive information for the cost of borrowing in other peripheral Eurozone economies. Noting that economists disagree on the definition of contagion and how it can be empirically tested (see Corsetti et al., 2011), our Greek-debt related Twitter/Facebook and Google Trends variables arguably comply with the thinking of Mink and de Haan (2013) who refer to contagion in terms of 
country-specific events and their impact on the asset prices of other countries.

Given that the data used in our case are unwrought, further qualitative elaboration may be of fathomless importance in revealing more clearly the true linkage between Greek-debt related social media/search queries and GIIPS spreads. With this in mind, our work, which relies on the B\&C test, differs from recent work by Arghyrou and Kontonikas (2012) who use monthly data to identify contagion effects in terms of a significant direct and positive effect from the Greek spread on other Eurozone sovereign spreads and more so for the remaining GIIPS (with the effect being stronger for Ireland and Portugal), or recent work by De Santis (2012) who identifies contagion effects in terms of the direct impact of a Greek credit rating downgrade on other Eurozone sovereign spreads (the impact is again stronger for Portugal and Ireland). Our work also differs from Beetsma et al. (2013) who construct macroeconomic/financial news variables about the GIIPS (using information from the newsflash of Eurointelligence; an independent internet-based service which provides daily morning euro-area news briefings of the European media) to conclude that bad news has increased sovereign yield differentials in the GIIPS and has triggered spillover effects to non-GIIPS countries. Finally, we also note the work of Di Cesare et al. (2013) who argue that recent movements in Eurozone spread differentials have increased to levels above those justified by economic fundamentals. Di Cesare et al. (2013) construct a monthly index of search volume of euro break-up keywords ("end of euro", "end of the euro", "euro break-up", "euro break") and note that this index has a strong positive correlation of 0.77 with the residual part of the 10 -year 
Italian spread, that is, the part not explained by economic fundamentals (such as the deficit-to-GDP ratio, expected growth, the volatility of stocks in the banking sector and the volatility of the Italian spread).

\section{Discussion and concluding remarks}

This paper examines the long and short-run causality between Google Trends (search queries) and Twitter/Facebook (social media) data related to the Greek debt crisis and sovereign spreads in the GIIPS. We have four main findings. First, there is neither short-run nor long-run causality running from the Greek spread to social media/search queries. Second, we identify short-run causality from social media/search queries to the Greek spread. Our evidence remains strong even when a number of financial controls are accounted for. This might be due to the fact that spreads, social media/search queries and controls are all driven by the same unknown underlying process (for instance, expectations could play an important role). Third, there is some sporadic (and information-set sensitive) evidence of predictability of Greek-debt related social media/search queries for Portuguese and Italian spreads (but not for Spanish or Irish spreads). Fourth, Google (search queries) carries different short-run predictive information relative to Twitter/Facebook. Although Google (search queries) is used by a wider base, Twitter/Facebook have both become a very popular way of keeping track of news and directing "followers" to news analysis (e.g. in blogs) in an extremely speedy way; this might explain why Twitter/Facebook provides (primarily for the Greek spread and to a lesser extent for the Portuguese spread) more pronounced evidence of short run predictability in terms of significance relative to Google (search queries). 
In fact, Twitter and Facebook do not necessarily function in the same way; Twitter is much more likely to get people to click through on links (Carr, 2010). Because of its broader mix of sources for news links, Twitter provides expanded knowledge compared to Facebook. Last but not least, Facebook users track with the general population very closely whereas Twitter users are more educated. ${ }^{11}$

A frequently made assumption is that the relationship between information demand and risk aversion is a positive one (see for instance Eeckhoudt and Godfroid 2000). Although opposite views to the latter have been expressed, in this paper we take the view that increased social media attention for the Greek crisis is considered as "bad news" 12 and drive up spreads on the grounds that it reflects increased concerns about Greek debt sustainability and the future of the Eurozone. A contrasting view is that social media might push spreads down if it reflects increased optimism about European support measures to prevent Greece from defaulting; in addition social media attention can be a response to endogenous events such as jumps in the Greek sovereign spread. Figure 1 provides more support for the former since we do observe that the three highest values of the Google Index appear in periods where increased uncertainty arises (the first one when the referendum was announced, the second one when the Greek parliament had to approve austerity measures and the last one during the Greek

\footnotetext{
${ }^{11}$ Facebook users get the majority (70\%) of the News links from Family/Friends and only a tiny share (13\%) from News organizations or Journalists; contrast this with Twitter users who get $36 \%$ of News links from Family/Friends and as much as $27 \%$ from News organizations or Journalists. For more detailed information, including statistics on differences in education, see e.g. Mitchell et al. (2012).

${ }^{12}$ Alternatively, frequently used terms include "animal spirits", "market psychology" and self-reinforcing waves of pessimism and optimism (see the theoretical framework proposed by Angeletos and La'O, 2013).
} 
elections). The evidence we provide implicitly assumes the following order: increased social media/search queries activity implies higher risk which results in a higher spread (clearly the reverse does not hold) ${ }^{13}$. This very issue is arguably a hostage to fortune. Indeed, it suggests that the more policymakers talk about the Greek debt crisis, and hence the more the social media refer to it, the more spreads will rise. A similar argument was put forward by David Smith, Economics Editor of The Sunday Times. Commenting on the launch of the Bank of England's new 'uncertainty gauge', which pools information from a set of financial market indicators and the number of press articles citing economic uncertainty, Smith noted that as policymakers intensify their talk about uncertainty, journalists write more about it which, in turn, adds further to uncertainty and damages economic growth (Smith, 2013).

Overall, our empirical results suggest that unwrought data, effortlessly traced in social media, enclose valuable information content with respect to the short-run movements of financial markets. We do not argue that the frequency of searches/appearances of a particular term is comparable to a sentiment index; rather, we flag the issue that it offers unexploited information which can be further utilized for improving our understanding of financial markets.

\footnotetext{
${ }^{13}$ Vlastakis and Markelos (2012) confirm empirically for US stocks that investors demand more information as their level of risk aversion increases.
} 


\section{References}

Angeletos, G.-M. and J. La'O (2013). Sentiments. Econometrica 81, 739-779.

Angelini, P., A. Nobili and C. Picillo (2011). The Interbank Market after August 2007: What Has Changed, and Why? Journal of Money, Credit and Banking 43, 924-958.

Arghyrou, M.G. and A. Kontonikas (2012). The EMU sovereign-debt crisis: Fundamentals, expectations and contagion. Journal of International Financial Markets, Institutions and Money 22, 658-677.

Bank of International Settlements Quarterly Review (2011). Table 9B: Consolidated Foreign claims of Reporting Banks. Data for End-June 2011. Available from http://www.bis.org/statistics/consstats.htm

Beetsma, R, M. Giuliodori, F. de Jong and D. Widijanto (2013). Spread the news: The impact of news on the European sovereign bond markets during the crisis. Journal of International Money and Finance 34, 83-101.

Bodart, V. and B. Candelon (2009). Evidence of interdependence and contagion using frequency domain framework. Emerging Markets Review $10,140-150$.

Breitung, J. and B. Candelon (2006). Testing for short and long-run causality: a frequency domain approach. Journal of Econometrics 132, 363-378.

Carr, A. (2010). Twitter Crushing Facebook's Click-Through Rate: Report. October 11 , 2010. Available from: http://www.fastcompany.com/1694174/twitter-crushing-facebooksclick-through-rate-report

Corsetti, G., M. Pericoli and M. Sbracia (2011). Correlation analysis of financial contagion. In: Kolb, R. (Ed.), Financial Contagion: The Viral Threat to the Wealth of Nations. Wiley, New York, pp. 11-20. 
Da, Z., J. Engelberg and P. Gao (2011). In search of attention. Journal of Finance 66, 1461-1499.

De Santis, R.A. (2012). The Euro area sovereign debt crisis-Safe haven, credit rating agencies and the spread of the fever from Greece, Ireland and Portugal. European Central Bank Working Paper No. 1419.

Di Cesare, A., G. Grande, M. Manna and M. Taboga (2013). Recent estimates of sovereign risk premia for Euro-area countries. Bank of Italy Occasional Papers No 128. Available from:

http://www.bancaditalia.it/pubblicazioni/econo/quest ecofin 2/qef128/ QEF 128.pdf

Eeckhoudt L. and P. Godfroid (2000). Risk Aversion and the Value of Information. Journal of Economic Education 31, 382-388.

Favero, C.A., M. Pagano, and E.L. Von Thadden (2010). How Does Liquidity affect Bond Yields? Journal of Financial and Quantitative Analysis 45, 107-134.

Geoffrey, P.S. (2012). Google internet search activity and volatility prediction in the market for foreign currency. Finance Research Letters 9, 103-110.

Hasan, I., K. Jackowicz, O. Kowalewski and Ł. Kozłowski (2012). Market Discipline during Crisis: Evidence from Bank Depositors in Transition Countries. The Wharton School University of Pennsylvania, Financial Institutions Center Working Paper No 12-12. Available from: http://fic.wharton.upenn.edu/fic/papers/12/12-12.pdf

Hosoya, Y. (2001). Elimination of third-series effect and defining partial measures of causality. Journal of Time Series Analysis 22, 537-554.

Joseph, K., M.B. Wintoki and Z. Zhang (2011). Forecasting abnormal stock returns and trading volume using investor sentiment: Evidence from online search. International Journal of Forecasting 27, 1116-1127. 
Kapetanios, G., Y. Shin and A. Snell (2003). Testing for a unit root in the nonlinear STAR framework, Journal of Econometrics 112, 359-379.

Mink, M. and J. de Haan (2013). Contagion during the Greek sovereign debt crisis. Journal of International Money and Finance 34, 102-113.

Mitchell, A., T. Rosenstiel and L. Christian (2012). What Facebook and Twitter Mean for News - The State of the News Media 2012, Pew Research Center's Project for Excellence in Journalism. Available from:

http://stateofthemedia.org/2012/mobile-devices-and-newsconsumption-some-good-signs-for-journalism/what-facebook-andtwitter-mean-for-news/

Naes, R., J.A. Skjeltorp and B.A. Ødegaard (2011). Stock Market Liquidity and the Business Cycle. Journal of Finance 66, 139-176.

Pan, W., Y, Altsuler and A. Pentland (2012). Decoding Social Influence and the Wisdom of the Crowd in Financial Trading Network. IEEE Social Computing.

Rosengren, E. (2010). The Impact of Liquidity, Securitization, and Banks on the Real Economy. Journal of Money, Credit and Banking 42, 221-228.

Schwarz (2010). Mind the gap. Disentangling credit and liquidity in risk spreads. Available at SSRN: http://ssrn.com/abstract=1486240.

Smith, D. (2013). Economic outlook: Productivity is down but don't count it out. The Sunday Times, 16 June 2013.

Vlastakis, N. and R.N. Markelos (2012). Information demand and stock market volatility. Journal of Banking and Finance 36, 1808-1821. 
Table 1: How social media predicts 10 -year sovereign spreads ( $\mathrm{Sj})$.

\begin{tabular}{|c|c|c|c|}
\hline $\begin{array}{c}\text { Country } \\
\text { j }\end{array}$ & $\begin{array}{c}\text { Predictability } \\
\text { without } \\
\text { conditioning }\end{array}$ & $\begin{array}{l}\text { Predictability with } \\
\text { conditioning (FSI) }\end{array}$ & $\begin{array}{l}\text { Predictability with } \\
\text { conditioning (VIX) }\end{array}$ \\
\hline \multicolumn{4}{|c|}{ Panel $A$ : Google search queries predict Spreads $\left(G \rightarrow S_{j}\right)$. All numbers refer to days. } \\
\hline Greece & $\begin{array}{l}\leq 2.56 \&[2.89- \\
20.26]\end{array}$ & $\leq 2.26 \&[3.22-15.32]$ & $\begin{array}{l}\leq 2.33 \&[3.12- \\
\quad 20.26]\end{array}$ \\
\hline Ireland & $\notin$ & $\notin$ & $\notin$ \\
\hline Italy & $\notin$ & $\not$ & [2.92-3.93] \\
\hline Portugal & $\notin$ & $\not$ & $\not$ \\
\hline Spain & $\not$ & $\not$ & $\notin$ \\
\hline \multicolumn{4}{|c|}{$\begin{array}{l}\text { Panel B: Twitter \& Facebook hits predict Spreads }\left(T \rightarrow S_{j}\right) \text {. All numbers refer to } \\
\text { days. }\end{array}$} \\
\hline Greece & $\leq 2.63$ & $\leq 2.84$ & $\leq 2.89$ \\
\hline Ireland & $\notin$ & $\notin$ & $\not$ \\
\hline Italy & $\notin$ & $\not$ & $\not$ \\
\hline Portugal & $\leq 2.65$ & $\not$ & $\notin$ \\
\hline & & & \\
\hline Spain & $\notin$ & $\notin$ & $\notin$ \\
\hline
\end{tabular}

Note: The table reports the Breitung and Candelon (2006) predictability test without/with Hosoya's (2001) conditioning. G refers to the Google search queries index for "Greek crisis", "Greek debt crisis", "Greece crisis", "Greek debt" and "Grexit". T refers to Twitter \& Facebook hits for "Grexit". $\notin$ denotes absence of predictability. VIX refers to the Volatility Index and FSI to a Financial Stress Index. 
Figure 1. The Google search queries index

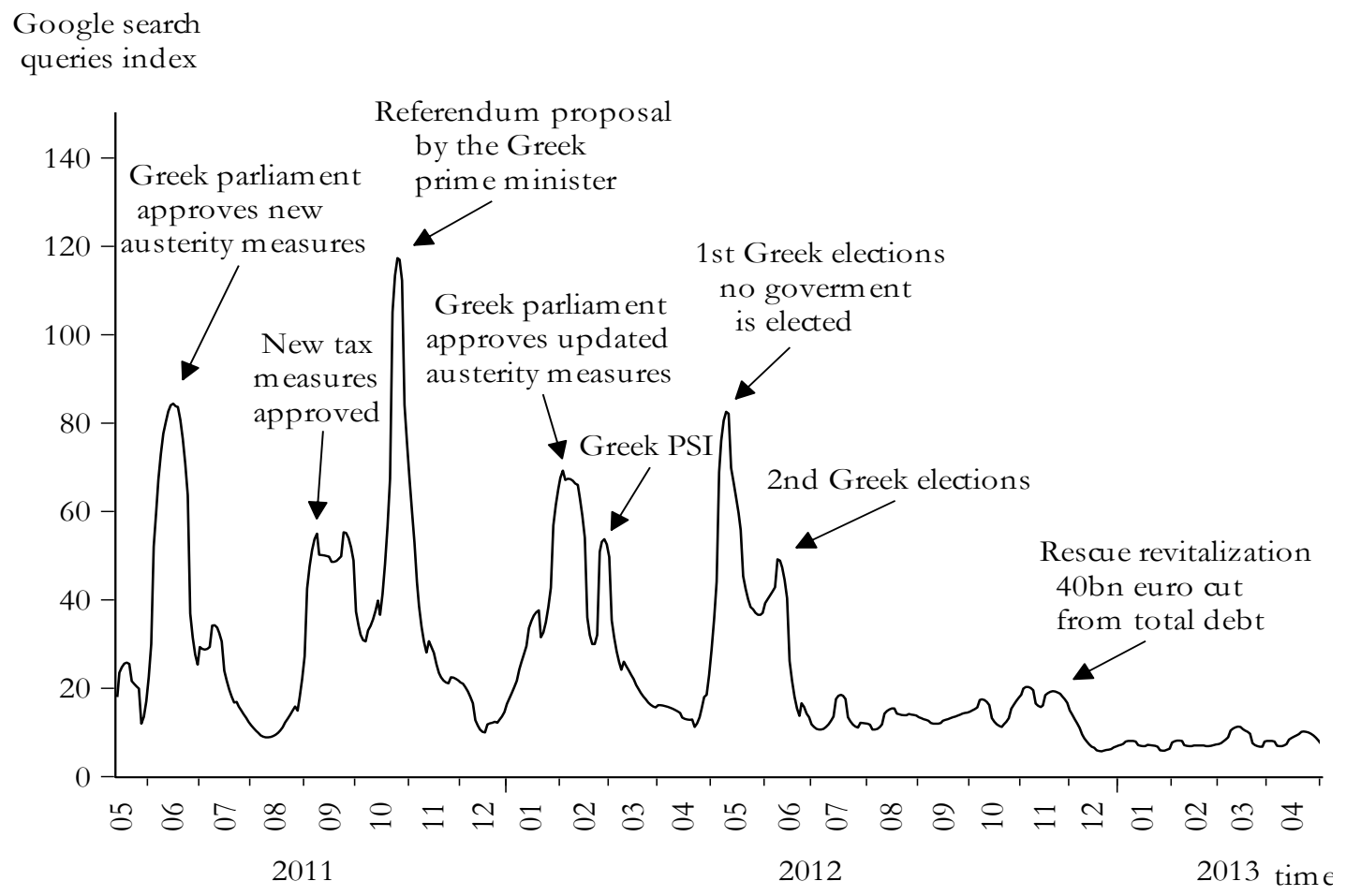

Note: PSI refers to Private Sector Involvement in the restructuring of Greek debt (February 2012). Greece, which was bailed-out twice (for $€ 110 \mathrm{bn}$ in 2010 and then again for $€ 109 \mathrm{bn}$ in 2011) negotiated, in February 2012, a new $€ 130$ bn rescue package involving a voluntary haircut of some $53.5 \%$ on the face value of its bonds held by the private sector. Eurozone ministers agreed (in November 2012) to cut Greece's debt by a further $€ 40 \mathrm{bn}$.

Figure 2. Twitter \& Facebook hits

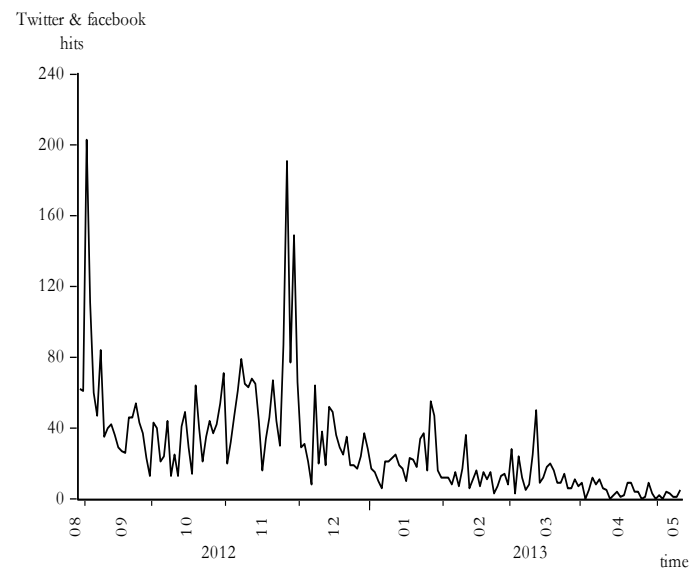

\section{Figure 3. GIIPS spreads}

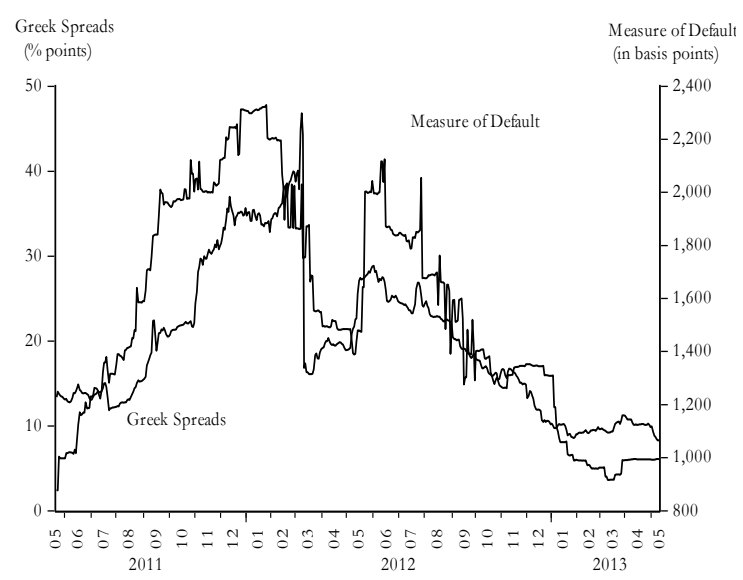


Figure 4. GIIPS default indices

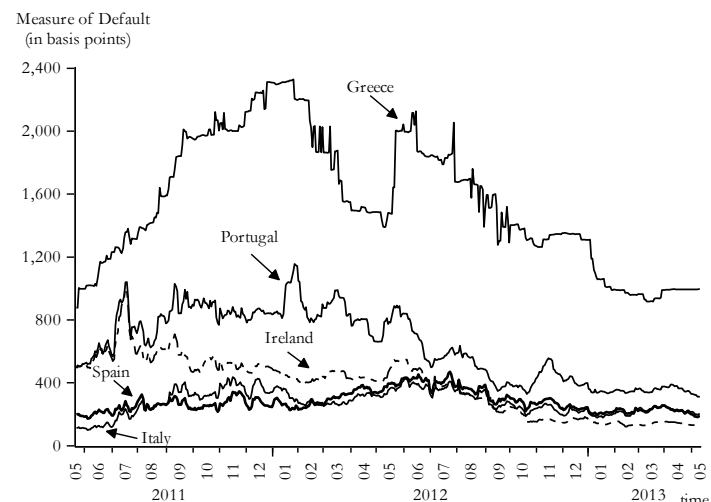

Figure 5. GIIPS liquidity risk \&

Eurozone risk factor

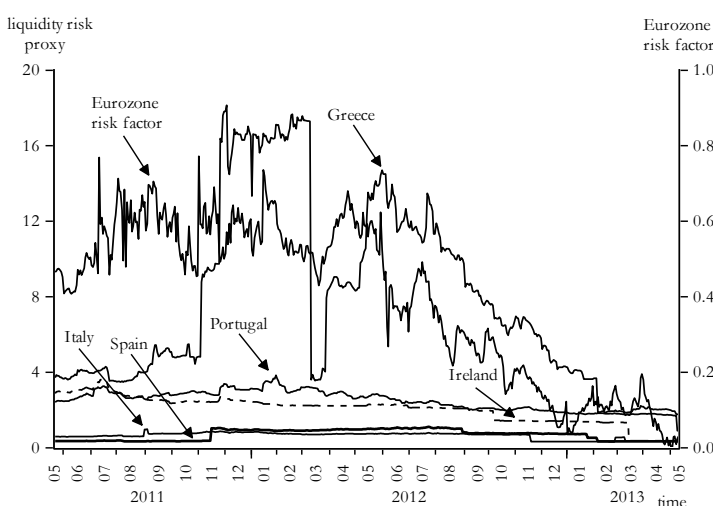

Note: In Fig. 5, liquidity risk (Lj) for country $\mathrm{j}$ is defined in terms of the percentage Bid-Ask spread:

$$
\begin{aligned}
& 100 *\left(\frac{A s k_{j}-B i d_{j}}{0.5 *\left(A s k_{j}+B i d_{j}\right)}\right)-100 *\left(\frac{A s k_{\text {Gemany }}-B i d_{\text {Germany }}}{0.5 *\left(A s k_{\text {Germany }}+B i d_{\text {Germany }}\right)}\right) \text {, where Ask and Bid refer to the Ask and Bid } \\
& \text { price of the 10-year government bond. }
\end{aligned}
$$

Figure 6. Financial Stress index \& VIX index

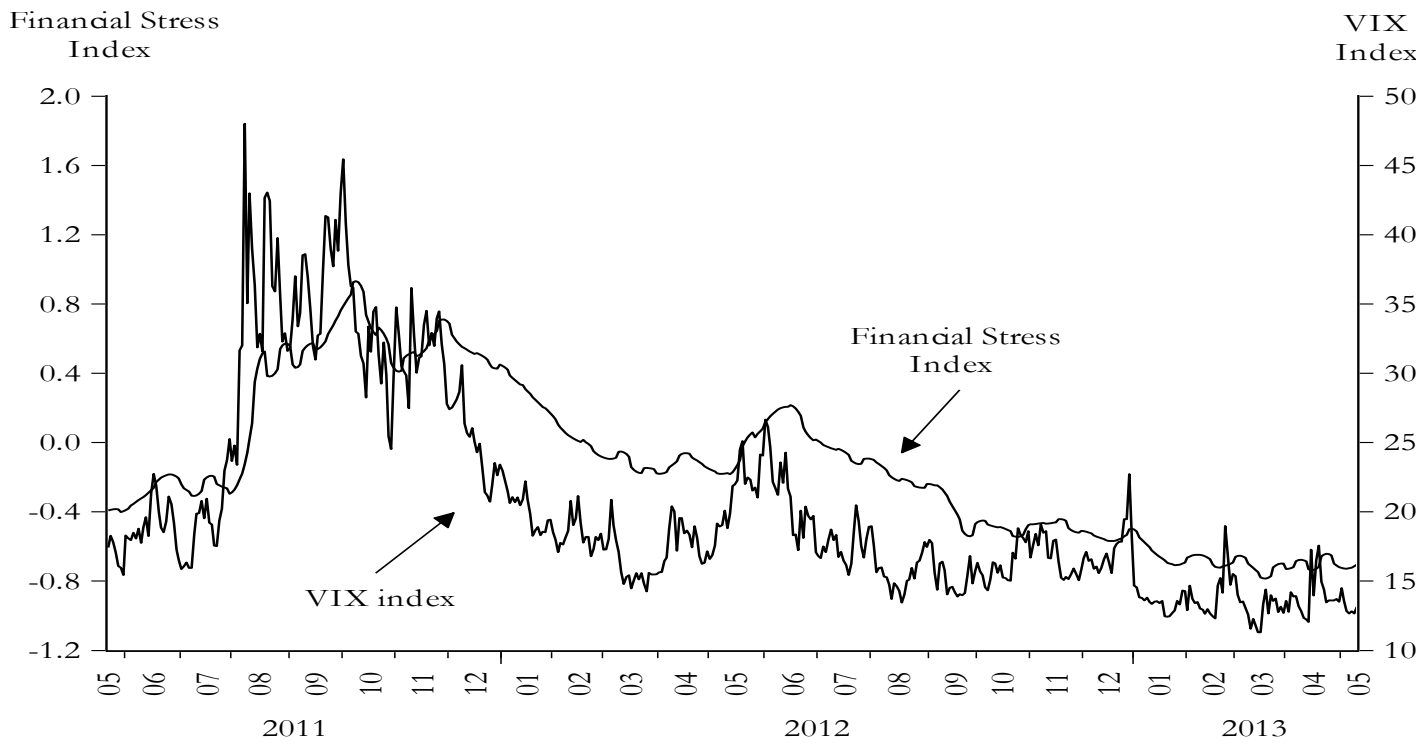


Figure 7. $G \rightarrow S_{\text {Greece }}$

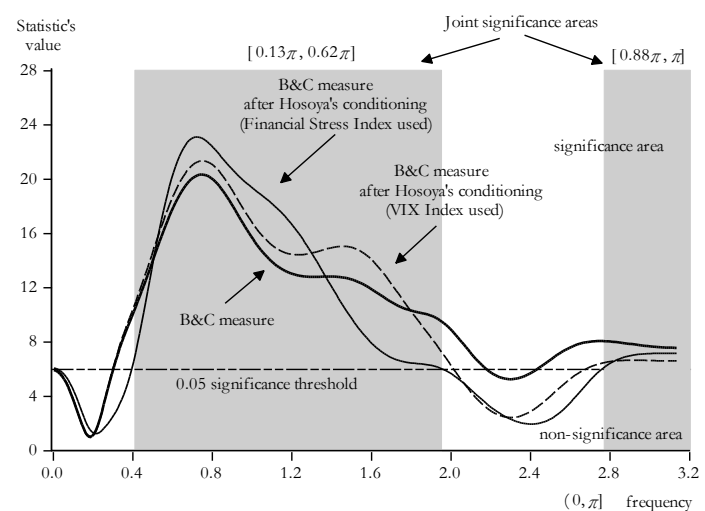

Figure 8. $T \rightarrow S_{\text {Greece }}$

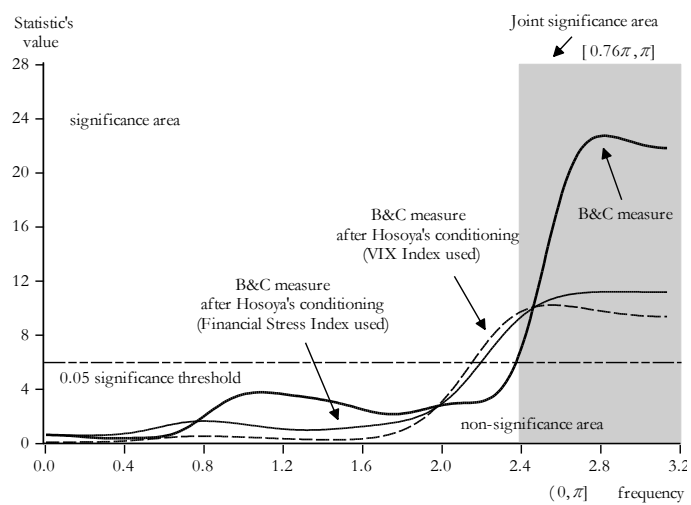

Note: In Fig. 7 the VAR lag length implemented for the derivation of the B\&C measure, the B\&C measure after Hosoya's conditioning using FSI and the B\&C measure after Hosoya's conditioning using VIX is 8,9 and 8 , respectively. Similarly, in Fig. 8 the VAR lag length is 8,5 and 5 , respectively.

Figure 9. $S_{\text {Greece }} \rightarrow G$

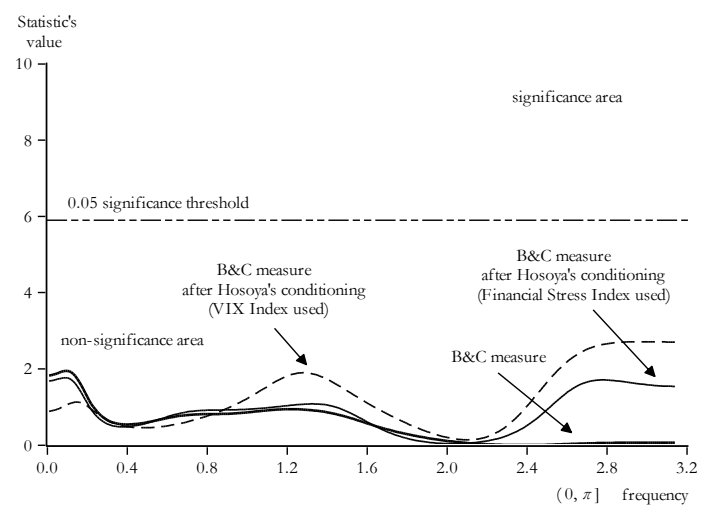

Figure 10. $S_{\text {Greece }} \rightarrow T$

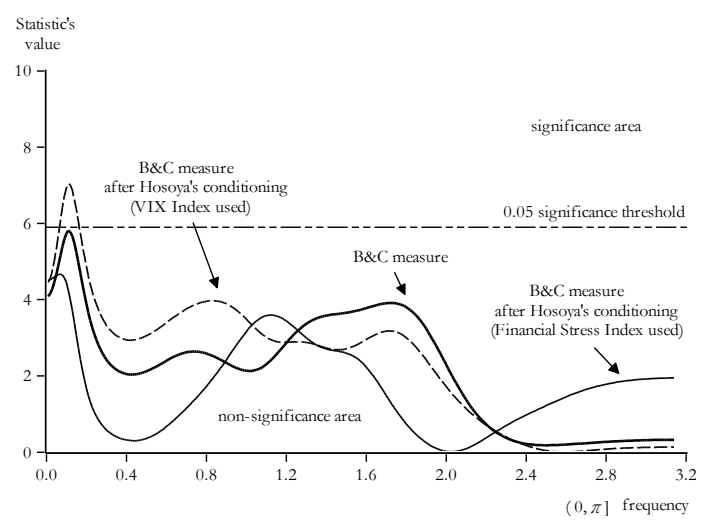

Note: In Fig. 9 the VAR lag length implemented for the derivation of the $B \& C$ measure, the B\&C measure after Hosoya's conditioning using FSI and the B\&C measure after Hosoya's conditioning using VIX is 8,8 and 7, respectively. Similarly, in Fig. 10 the VAR lag length is 8,9 and 9 , respectively. 
Figure 11. $G \rightarrow S_{\text {Ireland }}$

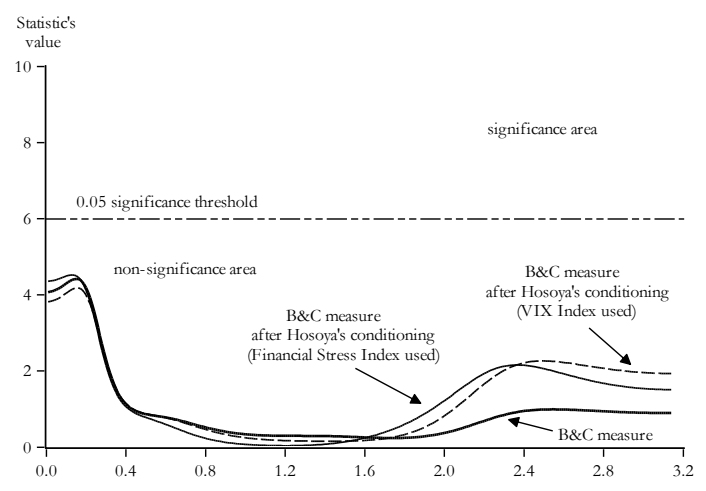

Figure 12. $G \rightarrow S_{\text {Italy }}$

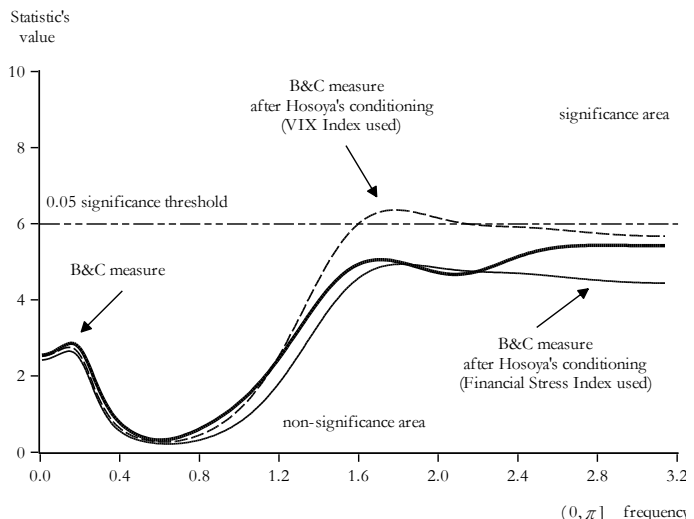

Note: In Figs. 11-12, the VAR lag length implemented for the derivation of the B\&C measure, the B\&C measure after Hosoya's conditioning using FSI and the B\&C measure after Hosoya's conditioning using VIX is 6 in every case.

Figure 13. $G \rightarrow S_{\text {Portugal }}$

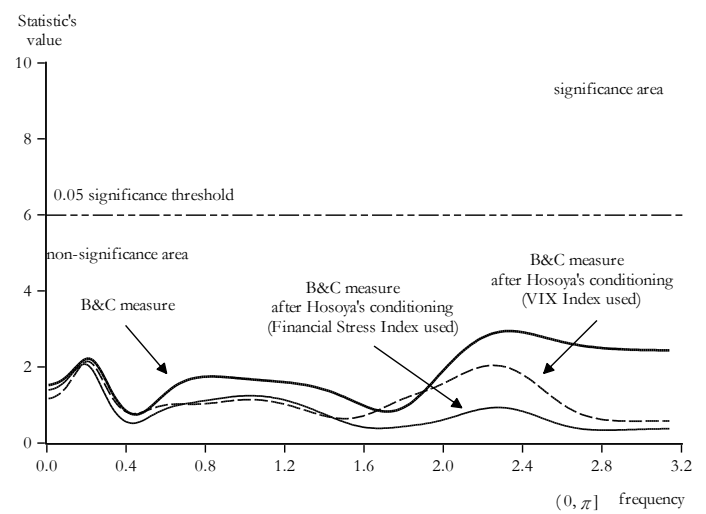

Figure 14. $G \rightarrow S_{\text {spain }}$

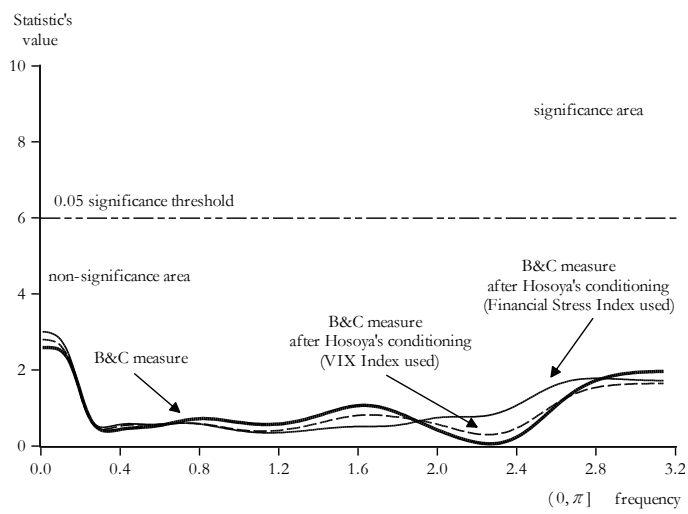

Note: In Fig. 13 the VAR lag length implemented for the derivation of the B\&C measure, the B\&C measure after Hosoya's conditioning using FSI and the B\&C measure after Hosoya's conditioning using VIX is 7,8 and 8 , respectively. Similarly, in Fig. 14 the VAR lag length is 8 in every case. 
Figure 15. $T \rightarrow S_{\text {Ireland }}$

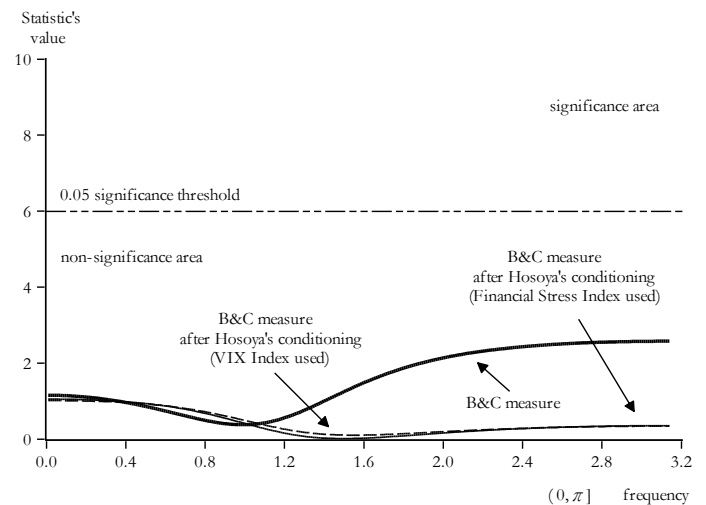

Figure 16. $T \rightarrow S_{\text {Italy }}$

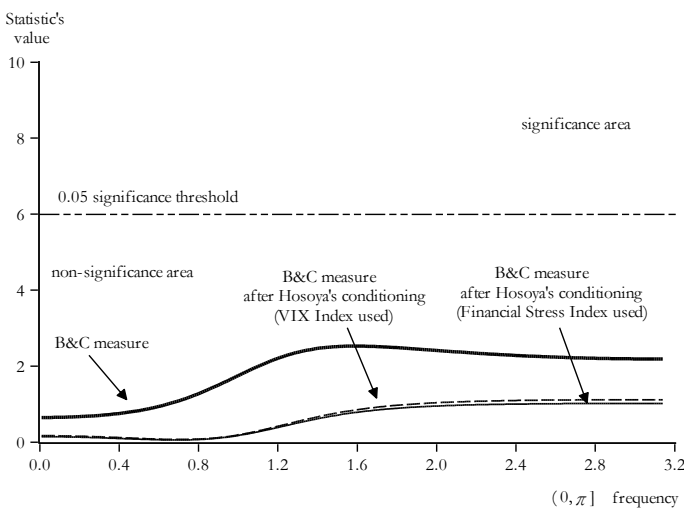

Note: In Figs. 15-16, the VAR lag length implemented for the derivation of the B\&C measure, the B\&C measure after Hosoya's conditioning using FSI and the B\&C measure after Hosoya's conditioning using VIX is 3 in every case.

Figure 17. $T \rightarrow S_{\text {Portugal }}$

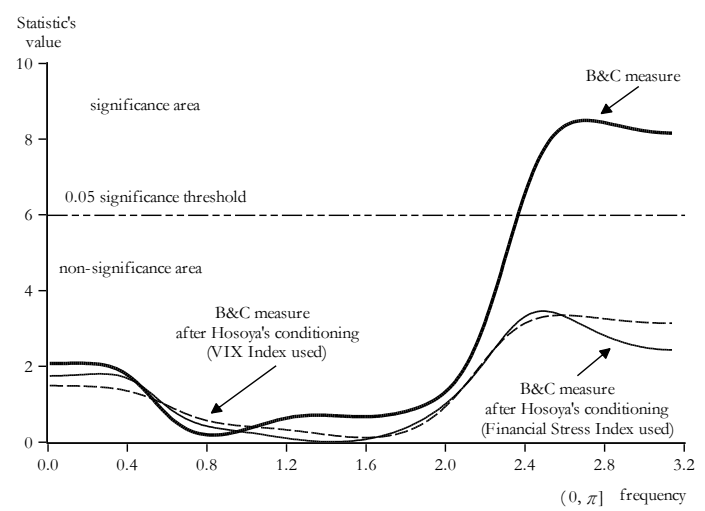

Figure 18. $T \rightarrow S_{\text {Spain }}$

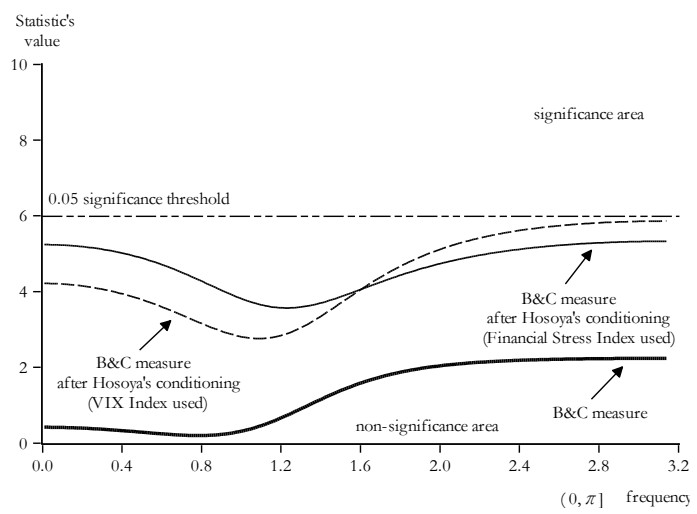

Note: In Fig. 17 the VAR lag length implemented for the derivation of the $B \& C$ measure, the B\&C measure after Hosoya's conditioning using FSI and the B\&C measure after Hosoya's conditioning using VIX is 6, 6 and 5, respectively. Similarly, in Fig. 18 the VAR lag length is 3 in every case. 


\section{Previous Papers in this Series}

77. Marangudakis, Manussos, Rontos, Kostas and Xenitidou, Maria, State Crisis and Civil Consciousness in Greece, October 2013

76. Vlamis, Prodromos, Greek Fiscal Crisis and Repercussions for the Property Market, September 2013

75. Petralias, Athanassios, Petros, Sotirios and Prodromídis, Pródromos, Greece in Recession: Economic predictions, mispredictions and policy implications, September 2013

74. Katsourides, Yiannos, Political Parties and Trade Unions in Cyprus, September 2013

73. Ifantis, Kostas, The US and Turkey in the fog of regional uncertainty, August 2013

72. Mamatzakis, Emmanuel, Are there any Animal Spirits behind the Scenes of the Euro-area Sovereign Debt Crisis?, July 2013

71. Etienne, Julien, Controlled negative reciprocity between the state and civil society: the Greek case, June 2013

70. Kosmidis, Spyros, Government Constraints and Economic Voting in Greece, May 2013

69. Venieris, Dimitris, Crisis Social Policy and Social Justice: the case for Greece, April 2013

68. Alogoskoufis, George, Macroeconomics and Politics in the Accumulation of Greece's Debt: An econometric investigation 1974-2009, March 2013

67. Knight, Daniel M., Famine, Suicide and Photovoltaics: Narratives from the Greek crisis, February 2013

66. Chrysoloras, Nikos, Rebuilding Eurozone's Ground Zero - A review of the Greek economic crisis, January 2013

65. Exadaktylos, Theofanis and Zahariadis, Nikolaos, Policy Implementation and Political Trust: Greece in the age of austerity, December 2012

64. Chalari, Athanasia, The Causal Powers of Social Change: the Case of Modern Greek Society, November 2012

63. Valinakis, Yannis, Greece's European Policy Making, October 2012

62. Anagnostopoulos, Achilleas and Siebert, Stanley, The impact of Greek labour market regulation on temporary and family employment Evidence from a new survey, September 2012 
61. Caraveli, Helen and Tsionas, Efthymios G., Economic Restructuring, Crises and the Regions: The Political Economy of Regional Inequalities in Greece, August 2012

60. Christodoulakis, Nicos, Currency crisis and collapse in interwar Greece: Predicament or Policy Failure?, July 2012

59. Monokroussos, Platon and Thomakos, Dimitrios D., Can Greece be saved? Current Account, fiscal imbalances and competitiveness, June 2012

58. Kechagiaras, Yannis, Why did Greece block the Euro-Atlantic integration of the Former Yugoslav Republic of Macedonia? An Analysis of Greek Foreign Policy Behaviour Shifts, May 2012

57. Ladi, Stella, The Eurozone Crisis and Austerity Politics: A Trigger for Administrative Reform in Greece?, April 2012

56. Chardas, Anastassios, Multi-level governance and the application of the partnership principle in times of economic crisis in Greece, March 2012

55. Skouroliakou, Melina, The Communication Factor in Greek Foreign Policy: An Analysis, February 2012

54. Alogoskoufis, George, Greece's Sovereign Debt Crisis: Retrospect and Prospect, January 2012

53. Prasopoulou, Elpida, In quest for accountability in Greek public administration: The case of the Taxation Information System (TAXIS), December 2011

52. Voskeritsian, Horen and Kornelakis, Andreas, Institutional Change in Greek Industrial Relations in an Era of Fiscal Crisis, November 2011

51. Heraclides, Alexis, The Essence of the Greek-Turkish Rivalry: National Narrative and Identity, October 2011

50. Christodoulaki, Olga; Cho, Haeran; Fryzlewicz, Piotr, $\underline{A \text { Reflection of }}$ History: Fluctuations in Greek Sovereign Risk between 1914 and 1929 , September 2011

\section{Online papers from the Hellenic Observatory}

All GreeSE Papers are freely available for download at http://www2.Ise.ac.uk/ europeanInstitute/research/hellenicObservatory/pubs/GreeSE.aspx

Papers from past series published by the Hellenic Observatory are available at http://www.Ise.ac.uk/collections/hellenicObservatory/pubs/DP oldseries.htm 